\title{
Diagnostic study of the influence of lateral boundary conditions for the REMO RCM simulations over the Carpathian Basin
}

\author{
G. Szépszó \\ Hungarian Meteorological Service, P.O. Box 38, 1525 Budapest, Hungary
}

Received: 29 December 2010 - Revised: 10 March 2011 - Accepted: 26 March 2011 - Published: 26 April 2011

\begin{abstract}
At the Hungarian Meteorological Service, two experiments were accomplished with the REMO5.0 regional climate model: (1) a simulation of a past period from 1961 to 2000, driven by the ECMWF ERA40 re-analysis data, and (2) a transient run from 1951 to 2100 driven by the ECHAM5/MPI-OM global coupled atmosphere-ocean model using SRES A1B forcing. The integration domain covers continental Europe with $25 \mathrm{~km}$ horizontal resolution in both experiments. Present article is dedicated to the investigation of the simulation results for the past period. The results for 1961-1990 were compared on the one hand with observations, and on the other hand, with each other and the corresponding global fields in order to assess the impact of the different lateral boundary conditions on the results focusing on the area of our interest, i.e., Hungary. The evaluation indicated that the re-analysis driven experiment provides warm and in summer dry past climate over the Carpathian Basin, whereas lower temperature and higher precipitation values are obtained when the lateral boundary information is derived from a global climate model. Based on the validation, it is concluded that the temperature characteristics in the simulation-driven case outperformed the experiment forced by quasi-perfect (i.e., re-analysis) data, however, similar apparent conclusion cannot be drawn for precipitation. This paper is undertaking to give deeper insight into the details and possible reasons for these outcomes.
\end{abstract}

\section{Introduction}

Recently the continuously improving global climate models (GCMs) are providing realistic projections for synoptic-scale characteristics of the climate, however, they are insufficient for detailed regional-scale estimations. The use of regional climate models (RCMs) ensures a dynamically based opportunity to enhance the global results for regional scale. The large-scale information for the regional simulations is coming from global models through the lateral boundary conditions (LBCs). Several experiments (Giorgi and Bates, 1989; Radu et al., 2008) provided evidence, that RCMs are able to reproduce the synoptic-scale climate features specified by the LBCs. Nevertheless, due to the limited area character and the higher resolution, they have to be capable of describing the small-scale physical processes. Moreover, the Big-

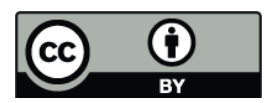

Correspondence to: G. Szépszó

(szepszo.g@met.hu)
Brother Experiments of Denis et al. (2002) showed, that not only the topography-induced patterns can be more realistically reflected by RCMs, but also the fine-scale processes forced by atmospheric nonlinearities and hydrodynamic instabilities due to the application of more sophisticated physical parameterization schemes.

The present study is dedicated to explore in detail the relation between the driving fields and driven regional climate models over the Carpathian Basin focusing on the period of 1961-1990 through a comparative analysis of the results of REMO regional climate model used at the Hungarian Meteorological Service (HMS) and its lateral boundary conditions as well as the observations. In Sect. 2 the most important characteristics of the accomplished experiments are introduced. Section 3 deals with thorough analysis of the results over Central Europe with special emphasis on the Hungarian territory. In Sect. 4 several open issues are discussed and the major conclusions are drawn. 


\section{Experimental design}

The REMO5.0 regional climate model was adapted at the Hungarian Meteorological Service in 2004. REMO (Jacob and Podzun, 1997) was developed by the Max Planck Institute for Meteorology in Hamburg based on the Europa Model, i.e., the former numerical weather prediction model of the German Weather Service, with the inclusion of the global ECHAM4's physical parameterization package. The physics of REMO5.0 and the current cycle of the ECHAM model (ECHAM5; Roeckner et al., 2003) are built on the same basis, however, ECHAM5 includes several improvements covering the parameterization of longwave radiation, cloud microphysics, etc. At the HMS two experiments were accomplished with the REMO model: (1) a simulation of a past period from 1961 to 2000, driven by the ERA40 reanalyses (Uppala et al., 2005), and (2) a transient run for the period of 1951-2100 driven by the ECHAM5/MPI-OM (Roeckner et al., 2003; Marsland et al., 2003) global coupled atmosphere-ocean model. (Hereafter, the simulations are referred to as ERA40-driven or REMO_ERA experiment and ECHAM-driven or REMO_ECHAM one, respectively.) In the (1951-2000) control period, the observed atmospheric concentrations of greenhouse gases and aerosols were taken for the global climate model integration, while for the 21st century these concentrations were prescribed according to the SRES A1B scenario (Nakicenovic et al., 2000). The regional integration domain was the same in both experiments: it covers continental Europe with $25 \mathrm{~km}$ horizontal resolution and in vertical 20 levels were applied. As far as the lateral boundary conditions are concerned, the horizontal resolution of the ERA-40 dataset is 1.125 degree (near $125 \mathrm{~km}$ ), while that of the ECHAM5 is 1.875 degree (approximately $200 \mathrm{~km}$ ).

The evaluation is addressing on the one hand, the validation, and on the other hand, the assessment of the influence of the different lateral boundary conditions on the results with special focus on Hungary. Therefore, the regional and global results were compared with the 10-min resolution monthly CRU (Mitchell and Jones, 2005) observational dataset and with each other and the driving fields for the period of 19611990. The validation was achieved for the 2-m mean temperature and precipitation amount, whereas the RCM-GCM intercomparison was extended with the investigation of 850$\mathrm{hPa}$ temperature and $700-\mathrm{hPa}$ relative humidity. (Validation of the last two parameters was not carried out in the absence of reliable and spatially homogenous measurements, though 850-hPa temperature provided by ERA-40 can be considered also as observation.) The reason for the choice of relative humidity was that despite the fact that specific humidity gives more direct information about the precipitation potential of the atmosphere than relative humidity, the evaluation of the latter one also provides an insight into the moisture and precipitation conditions of the simulations, especially in the summer months.

\section{Results}

\subsection{Temperature}

Investigating the results of the ERA40-driven simulation, it can be generally concluded, that REMO5.0 produces too high 2-m temperature values in every season almost over the whole integration area (not shown). This overestimation is especially large over Southern and Eastern Europe, particularly over Hungary it exceeds $3{ }^{\circ} \mathrm{C}$ in summer (however, in winter it remains under $0.5^{\circ} \mathrm{C}$ ). In the case of ECHAMdriven simulation, the seasonal 2-m temperature differences between the model results and observations are small indicating rather perfect annual simulation with less than $1{ }^{\circ} \mathrm{C}$ systematic error over the large part of the domain. Some exceptions are found over the Alps and Southeast from the Carpathian Basin: while in the elevated points the model underestimates the mean temperature, over the southeastern area it predicts too warm climate for the 1961-1990 reference period. Nevertheless, the errors do not reach $3{ }^{\circ} \mathrm{C}$ even at these "critical" regions and over Hungary the departure remains under $0.5^{\circ} \mathrm{C}$ in every season. It has to be remarked here, that the abovementioned mean temperature errors are calculated by comparison of the raw simulation data and the CRU dataset interpolated to the 0.22 -degree resolution model grid. If an altitude correction is applied for the raw temperature values to eliminate the differences between the orography of the model and reference dataset, the large over- and underestimations become deeper exceeding $3{ }^{\circ} \mathrm{C}$ over both regions. This is due to the structure of the differences between the two topographies: the northern and eastern slopes (i.e., the lee side) of the high mountains are more highly elevated, while the western and southern parts are lower in REMO than in the case of observations. This pattern implies that there is a shift between the orography fields. Nevertheless, same correction method is not utilized for the results over Hungary, because the target region is a relatively flat area without high orographic features.

The different performance of the two simulations (which differ from each other only in their lateral boundary conditions) can be also demonstrated in the relation between the driven regional and the driving global fields. It can be seen in Fig. 1, that the RCM introduces a systematic heating into the global results. This warming is almost constant along the reference period, however, its magnitude is lower in the ECHAM-driven case than in the ERA40-driven experiment (annually 0.9 and $2.2^{\circ} \mathrm{C}$ for Hungary, respectively; Table 1). The higher warming effect in the REMO_ERA simulation led to the identified large temperature overestimation over Hungary (since apart from its minor negative bias, the ERA40 dataset reproduces realistically the observed mean temperature values), whereas in the ECHAM-driven case it manifested as an improvement of the too low temperature values provided by ECHAM (Fig. 1). Based on the outcomes of the re-analysis driven simulation, one can conclude that 

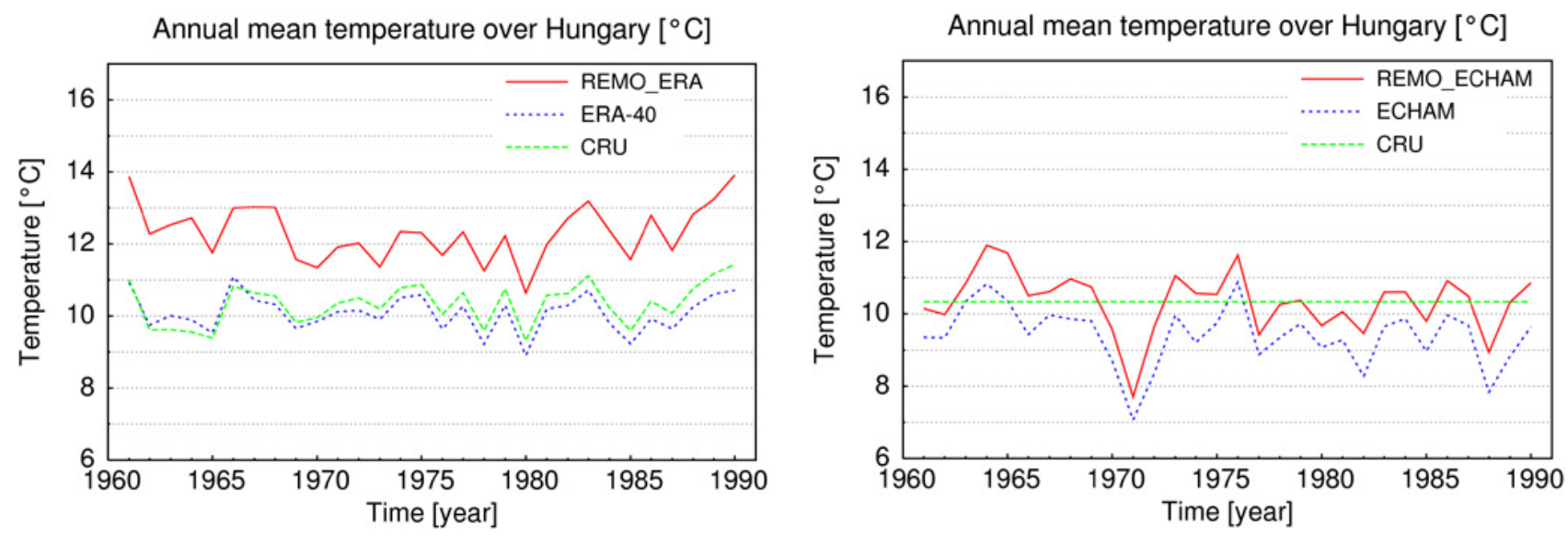

Figure 1. Evolution of the annual mean 2-m temperature $\left[{ }^{\circ} \mathrm{C}\right]$ in the REMO simulations (red curves: ERA40-driven REMO on the left, ECHAM-driven REMO on the right), the corresponding global fields (blue curves: ERA40 on the left, ECHAM5/MPI-OM on the right) and the CRU1.2 observation (green curve on the left) and its 30-year mean (green line on the right) over Hungary for 1961-1990.

Table 1. Mean temperature differences $\left[{ }^{\circ} \mathrm{C}\right]$ between the REMO simulations and the corresponding driving fields (ERA40-driven REMO and ERA40, ECHAM-driven REMO and ECHAM5/MPI-OM), the two regional simulations (REMO_ERA and REMO_ECHAM) and the two global fields (ERA40 and ECHAM5/MPI-OM) at $2 \mathrm{~m}$ and $850 \mathrm{hPa}$ over Hungary for 1961-1990.

\begin{tabular}{lcc|cc|cc|rr}
\hline & \multicolumn{2}{l}{$\begin{array}{l}\text { REMO_ERA } \\
\text { - ERA }\end{array}$} & \multicolumn{2}{l|}{$\begin{array}{l}\text { REMO_ECHAM } \\
\text { - ECHAM }\end{array}$} & \multicolumn{2}{l|}{$\begin{array}{l}\text { REMO_ERA } \\
\text { - REMO_ECHAM }\end{array}$} & \multicolumn{2}{l|}{ ERA-ECHAM } \\
\hline T2m & T850 & \multicolumn{2}{|l|}{ T2m } & T850 & T2m & T850 & T2m & T850 \\
\hline Annual & 2.2 & 2.9 & 0.9 & 0.8 & 2.0 & 1.8 & 0.7 & -0.3 \\
Spring & 1.7 & 2.6 & 0.8 & 0.8 & 1.8 & 1.8 & 0.9 & 0 \\
Summer & 3.6 & 3.1 & 1.2 & 0.7 & 3.5 & 2.8 & 1.1 & 0.4 \\
Autumn & 3.1 & 3.1 & 1.1 & 0.9 & 2.6 & 2.3 & 0.6 & 0.1 \\
Winter & 0.5 & 2.7 & 0.6 & 0.9 & 0.1 & 0.5 & 0.2 & -1.3 \\
\hline
\end{tabular}

REMO tends to overestimate the temperature over Hungary. Moreover, considering the re-analysis fields as perfect LBCs, this overestimation is coming (almost) purely from the regional climate model. This heating effect with respect to the global forcing exists also in the ECHAM-driven simulation, however, in this case the errors stemming from the RCM and GCM (over- and underestimation, respectively) have the same magnitude. Consequently, they cancel each other resulting in a "perfect" temperature simulation over the area of our interest.

The temperature departure between the regional and the corresponding global results is varying with the altitude, as well (Table 1): compared the 850-hPa differences to the 2$\mathrm{m}$ ones, they mainly enhance in the re-analysis driven case, especially in winter (and excluding summer), while using GCM forcings it is slightly reduced in most seasons (except winter). Parallelly to that, the deviation between the two global datasets is decreasing at higher level: it is lower at $850 \mathrm{hPa}$ than at $2 \mathrm{~m}$, though the ECHAM fields are still colder than the ERA40 ones, apart from winter. Based on these results one can conclude, that the divergence between the two regional temperature simulations is larger for the near-surface, and it is decreasing with the altitude, except winter (Table 1). In winter, contrary to its general "behaviour", ECHAM is much warmer at $850 \mathrm{hPa}$ than ERA40 (the difference exceeds $1{ }^{\circ} \mathrm{C}$ ). This is valid not only over Hungary, but also over the northern and eastern parts of the domain (Fig. 2), where the two regional simulations look more alike than it is the case for their global counterparts. Nevertheless, over South the abovementioned structure can be concluded again: the ERA40 and REMO_ERA fields have higher 850-hPa temperature values than the ECHAM and REMO_ECHAM ones, respectively.

Looking at the relation between the mean 2-m temperature errors and the simulated temperature values (for Hungary), a further important and interesting feature is found. In Fig. 3 the monthly mean departures from the observations are displayed as a function of the mean values provided by the $\mathrm{RCM}$, averaged for the 30-year reference period in each gridpoint. The simulation errors are strongly enhancing with the 
DJF mean temperature at $850 \mathrm{hPa}\left[{ }^{\circ} \mathrm{C}\right]$
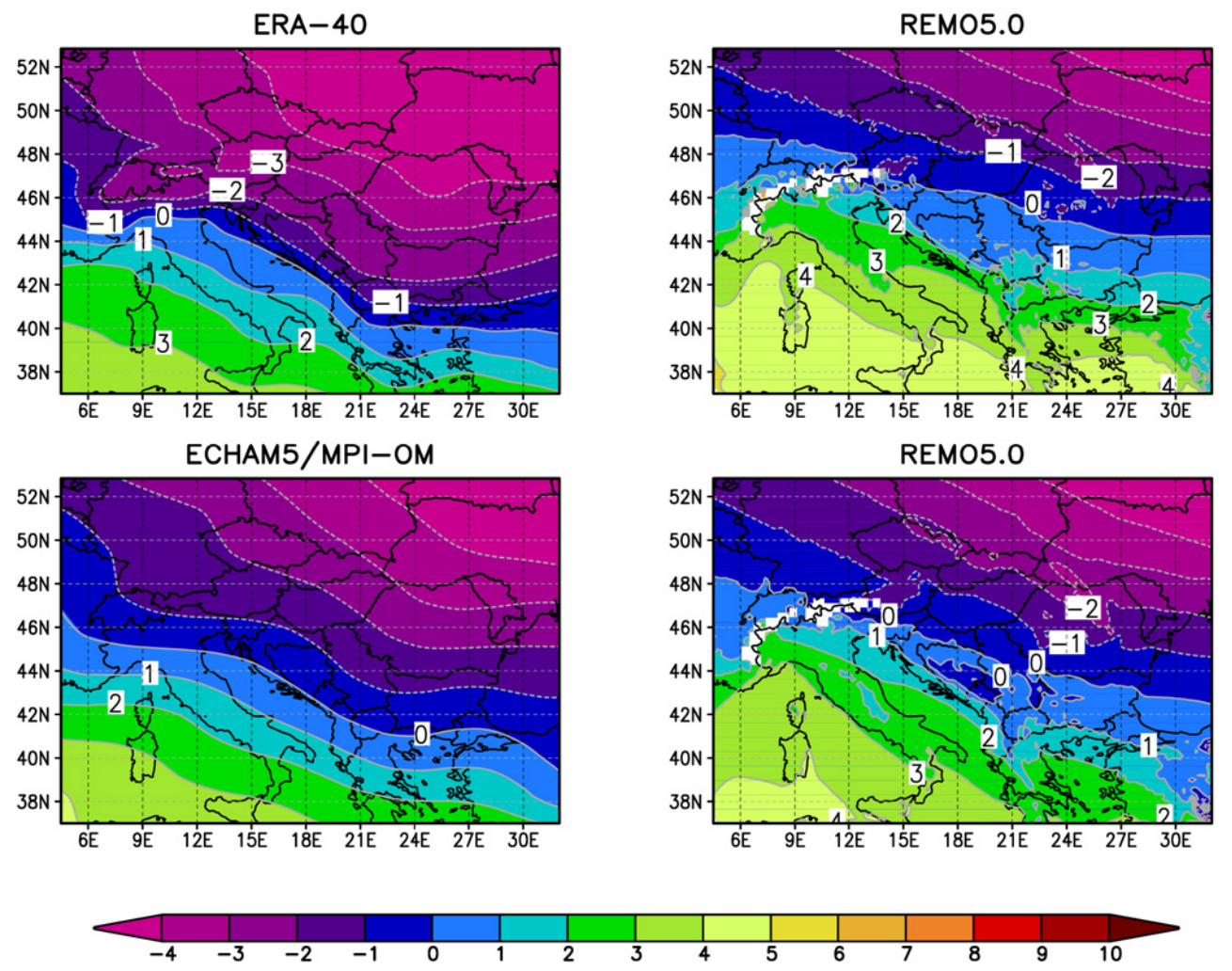

Figure 2. Winter mean temperature $\left[{ }^{\circ} \mathrm{C}\right]$ at the level of $850 \mathrm{hPa}$ in the REMO simulations (top right: ERA40-driven REMO, bottom right: ECHAM-driven REMO) and the corresponding global fields (top left: ERA40, bottom left: ECHAM5/MPI-OM) for 1961-1990.

increasing simulated value at the re-analysis driven results: the errors are between -1 and $+2{ }^{\circ} \mathrm{C}$ if the projected monthly mean temperature is between -5 and $5^{\circ} \mathrm{C}$ (i.e., in winter), while the errors reach even $5^{\circ} \mathrm{C}$ if the range of the simulated temperature covers $20-25^{\circ} \mathrm{C}$ (in summer and autumn). Using ECHAM fields as LBCs, the same behaviour cannot be observed and the temperature errors are principally independent of the simulated value: they are basically between -1 and $+2{ }^{\circ} \mathrm{C}$ for every temperature range. It is proved (but not shown here) that this special feature does not originate from the regional model itself, but the global driving fields already possess these error characteristics. I.e., the re-analysis dataset has the largest inaccuracies in the summer-autumn period, while the performance of the ECHAM5/MPI-OM results is basically not sensitive to the simulated temperatures. In order to find some explanation for this phenomenon it is worthwhile to investigate the link between temperature and precipitation simulations, which is discussed in the next subsection.

\subsection{Precipitation and relative humidity}

Regarding the mean annual precipitation errors (Fig. 4), one can immediately notice that REMO_ECHAM generates more precipitation than REMO_ERA. REMO (using either re-analysis LBCs or GCM ones) exaggerates the precipitation over the highest orographic features of Europe, the Alps and the Carpathians (to a lesser extent). However, the strongest overestimation is not always located over the mountain peaks, but rather over the slopes. The southern parts of the domain are characterized with underestimation (varying between 10 and 50\%) even over the mountains, like the Adriatic side of the Alps, the Dinaric Alps or the southern ranges of the Carpathians. The Carpathian Basin is situated in an intermediate zone: North from Hungary the regional simulations have positive bias (precipitation overestimation), while in South rather the underestimation is typical.

As far as the results over Hungary are concerned, even though REMO with ERA40 driving produces realistic seasonal precipitation cycle (not shown), in summer and autumn the results are hampered by some underestimation. Using ECHAM results as LBCs, the regional simulation generates too high precipitation amounts, except in summer, when REMO reproduces the mean precipitation with the greatest 

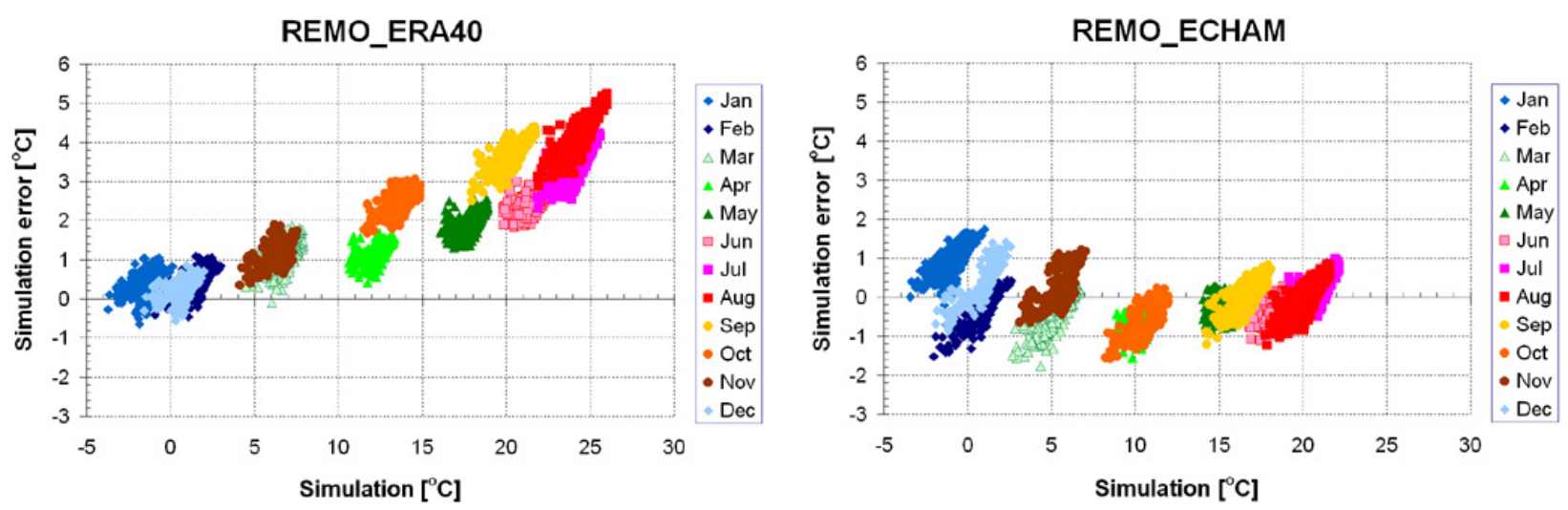

Figure 3. ERA40-driven (left panel) and ECHAM-driven (right panel) REMO simulation errors for monthly mean 2-m temperature [ $\left.{ }^{\circ} \mathrm{C}\right]$ with respect to the simulated values $\left[{ }^{\circ} \mathrm{C}\right]$ averaged for 1961-1990 in every gridpoint over Hungary. The reference dataset was provided by CRU1.2.
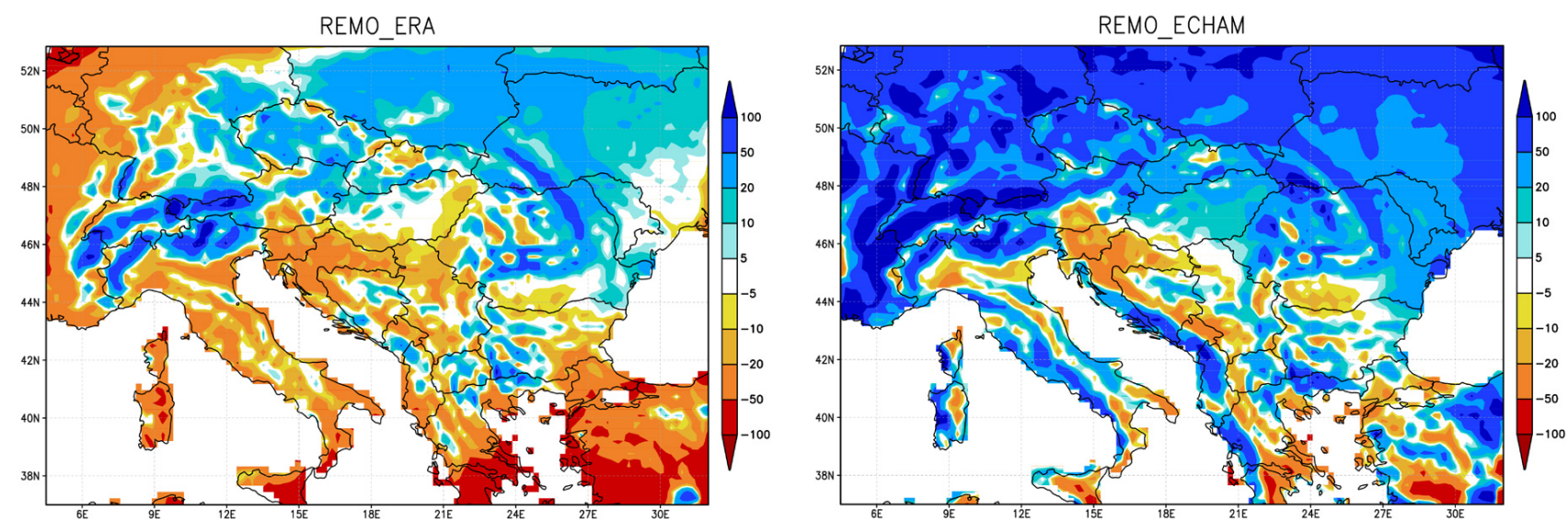

Figure 4. Relative annual precipitation difference [\%] between the REMO simulations (ERA40-driven REMO on the left, ECHAM-driven REMO on the right) and the CRU1.2 observations for 1961-1990.

skill. (More details about the ECHAM-driven simulation results can be read in Szépszó and Horányi, 2008.) Investigating simultaneously the mean temperature and precipitation simulation errors (Fig. 5), it can be discovered, that in the case of REMO_ERA the higher temperature overestimations (over $2.5^{\circ} \mathrm{C}$ ) correspond with the deepest precipitation underestimations (exceeding 15\%) in the August-October period. The large precipitation deficit in summer and autumn leads to drying the soil, which makes even worse the general positive error in temperature and this process can induce the results seen in Fig. 3. The same mechanism cannot be experienced in the case of REMO_ECHAM: here a precipitation surplus can be rather concluded at the end of summer and beginning of autumn, which is accompanied by only small temperature errors not larger than $0.5^{\circ} \mathrm{C}$.

Comparing the mean precipitation fields in the driving global and the corresponding regional models (not shown), REMO predicts significantly more precipitation than the global fields especially over the highly elevated areas, but also in vicinity of some borders of the integration domain.
The excessive precipitation over the mountains in the fineresolution models compared to the coarse-resolution ones is a well-known property of the numerical models. The influence of the orography is visible over the Alpine region also in the relative humidity at the level of $700 \mathrm{hPa}$ (see Fig. 6 for summer). The spurious features near to the domain borders might come from the numerical treatment of lateral boundaries, when false reflecting waves appear along the edges, which are caused by the "imbalances" between the global and regional fields in the boundary zone. However, it has to be remarked, that in this context precipitation acts as an indicator of this effect, since it is not a coupled, but a diagnostic variable. Therefore, it is more proper to investigate the departures between the regional and global fields for a humidityrelated prognostic variable (for instance specific humidity). In our study, the 700-hPa humidity field is considered, however, the noises at higher levels are naturally "smoother" than at the near-surface. At $700 \mathrm{hPa}$, the abovementioned boundary effect is more emphasized in the case of REMO_ECHAM simulation, since the driving ECHAM fields supply more 


\section{REMO_ERA40}

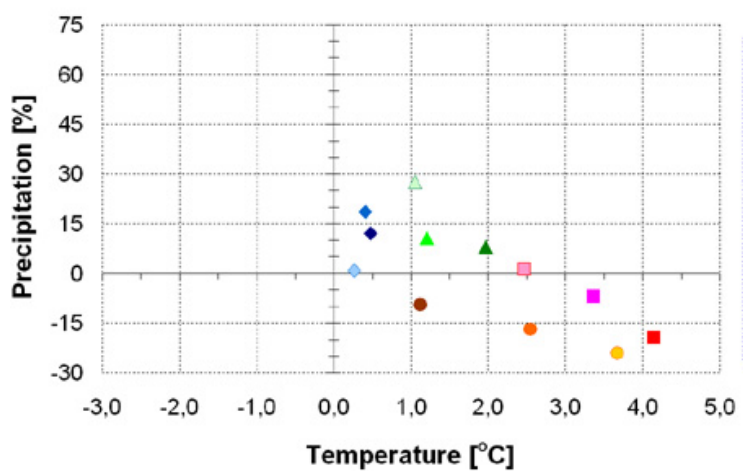

REMO_ECHAM

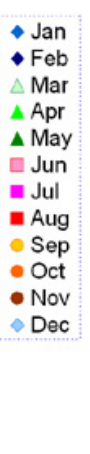

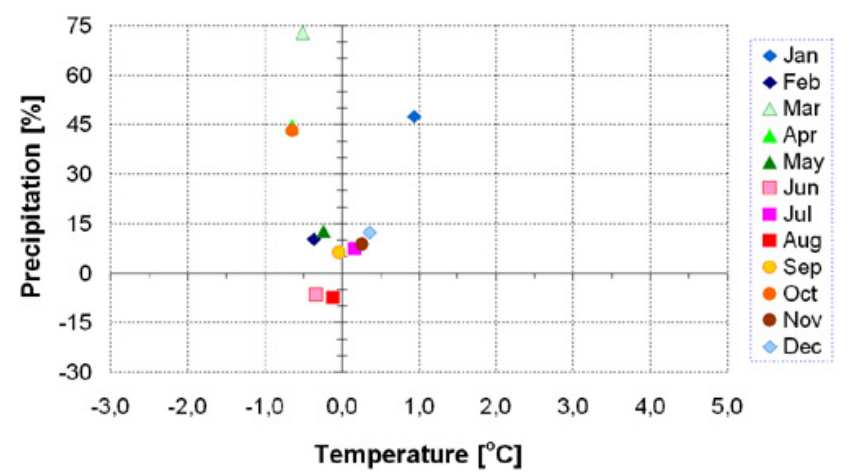

Figure 5. Monthly mean precipitation and temperature differences [\% and ${ }^{\circ} \mathrm{C}$, respectively] between the REMO simulations (ERA40-driven REMO on the left, ECHAM-driven REMO on the right) and the CRU1.2 observations over Hungary for 1961-1990.

\section{JJA mean relative humidity at $700 \mathrm{hPa}$ [\%]}
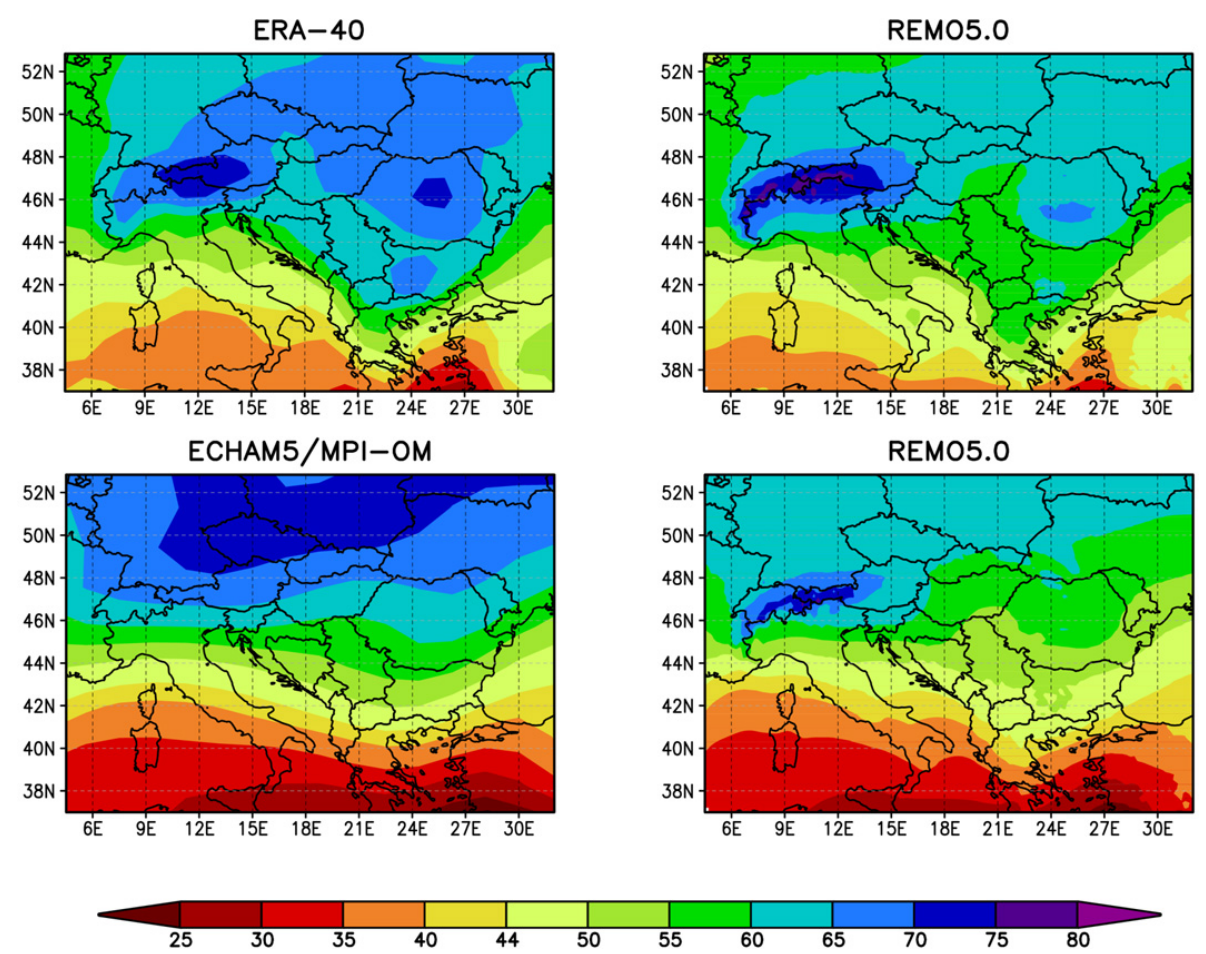

Figure 6. Summer mean relative humidity [\%] at the level of $700 \mathrm{hPa}$ in the REMO simulations (top right: ERA40-driven REMO, bottom right: ECHAM-driven REMO) and the corresponding global fields (top left: ERA40, bottom left: ECHAM5/MPI-OM) for 1961-1990.

relative humidity, particularly over the northern part of the domain than the re-analyses (Fig. 6). Nevertheless, the regional fields at this level are dryer than the global ones, and linking this fact together with the surface precipitation surplus, it allows to conclude, that the higher-level humidity disappears from the atmosphere in the form of precipitation. (The confirmation of this issue requires the investigation of near-surface humidity and specific humidity.)

\section{Conclusions and discussion}

In the present study the results of two REMO5.0 regional climate model experiments were evaluated: a past simulation driven by the measurement-based (therefore, supposed to be quasi-perfect) ERA40 re-analysis data and a transient climate change simulation where the large-scale forcings were originated from the ECHAM5/MPI-OM AOGCM. The regional model results were analysed for the period of 1961-1990 in 
order to validate them with respect to the observations and to estimate the impact of the different lateral boundary conditions on the regional outcomes.

According to the validation it can be concluded, that the re-analysis driven experiment provides generally warm and in summer dry past climate over the Carpathian Basin, whereas lower temperature and higher precipitation values are obtained when the lateral boundary information is derived from a global climate model simulation. Over Hungary REMO5.0 brings a heating into the global results, which is larger and increasing with the height in ERA40-driven case. The same but more moderate effect in the GCM-driven simulation improves the originally too low near-surface temperature values provided by ECHAM. The 700-hPa results indicate that the regional model drains the global fields, which is more robust in the case of initially more humid GCM LBCs. Regarding the precipitation results, with the ECHAM LBCs REMO5.0 produces high overestimation over large part of the integration domain. There are some open issues not fully answered by this diagnostic study, hereafter they are briefly listed with some possible explanation:

- The GCM-driven regional temperature simulation performs better compared to the re-analysis driven one. In the latter case, due to the quasi-perfect characteristics of the LBCs, (in theory) validation provides information exclusively about the deficiencies of the regional model. Contrary to that, in the GCM-driven case the errors of the RCM and the GCM cannot be separated, they interact and might cancel each other. However, since also the ERA40 dataset has some known deficiencies, they determine the performance of the RCM results in the same way as using driving fields from a GCM.

- Applying re-analyses as LBCs, the temperature errors are sensitive to the simulated values, at the same time this feature is not detected at GCM-driven results. This different behaviour might be caused by the cooccurrences of high temperature overestimations and large precipitation underestimations at the end of summer and beginning of autumn in the re-analysis driven experiment. This "constellation" can affect the soil wetness towards drying, and the soil circumstances providing surface forcings for the model has great influence on the atmospheric simulation and can make more severe the positive temperature bias. Same coincidences regarding temperature and precipitation cannot be concluded in the case of REMO_ECHAM simulation.

- REMO inevitably provides some additional nearsurface heating with respect to the global driving fields, however this warming is smaller in the case of ECHAM5 driving than that of the ERA40 one (its reason is to be explored). The REMO_ECHAM 2-m temperature simulations are rather perfect due to the error cancellation between the global and regional mod- els. This heating effect makes dry the regional fields at higher levels, but for precipitation the opposite is valid. This latter outcome suggests that the humidity, which "disappears" at the higher atmospheric levels from the regional model, falls out near the surface as precipitation. This conclusion raises the necessity of the investigation of specific humidity, which is an absolute measure of the atmospheric moisture and providing more accurate information about the quantity of precipitable water vapour in the atmosphere.

As summary, this diagnostic study raises several questions, which were not completely explained, but are worthwhile to be deeply examined. The ideas gathered in current paper pinpoint the "track" of our future investigations.

Acknowledgements. This work was supported by the European Commission's 6th Framework Programme in the framework of CLAVIER project (contract number 037013). The ECHAM5/MPIOM data were provided by the World Data Center for Climate in Hamburg. The author is grateful to the colleagues at the Max Planck Institute for the Meteorology in Hamburg for their help in adaptation of the REMO model. The useful comments and suggestions of the two anonymous referees are also highly appreciated.

Edited by: A. M. Sempreviva

Reviewed by: two anonymous referees

\section{SC $\mid$ nat $\begin{aligned} & \text { The publication of this article is sponsored } \\ & \text { by the Swiss Academy of Sciences. }\end{aligned}$}

\section{References}

Denis, B., Laprise, R., Caya, D., and Cote, J.: Downscaling ability of one-way nested regional climate models: the Big-Brother Experiment, Clim. Dynam., 18, 627-646, 2002.

Giorgi, F. and Bates, G.: The climatological skill of a regional model over complex terrain, Mon. Weather Rev., 117, 23252347, 1989.

Jacob, D. and Podzun, R.: Sensitivity studies with the regional climate model REMO, Meteorol. Atmos. Phys., 63, 119-129, 1997.

Marsland, S. J., Haak, H., Jungclaus, J. H., Latif, M., and Röske, F.: The Max Planck Institute global ocean/sea-ice model with orthogonal curvilinear coordinates, Ocean Model., 5, 91-127, 2003.

Mitchell, T. D and Jones, P. D: An improved method of constructing a database of monthly climate observations and associated highresolution grids, Int. J. Climatol., 25, 6, 693-712, 2005.

Nakicenovic, N., Alcamo, J., Davis, G., de Vries, B., Fenhann, J., Gaffin, S., Gregory, K., Grübler, A., Jung, T. Y., Kram, T., La Rovere, E. L., Michaelis, L., Mori, S., Morita, T., Pepper, W., Pitcher, H., Price, L., Raihi, K., Roehrl, A., Rogner, H.-H., Sankovski, A., Schlesinger, M., Shukla, P., Smith, S., Swart, R., van Rooijen, S., Victor, N., and Dadi, Z.: IPCC special report on emissions scenarios, Cambridge University Press, Cambridge, 2000 . 
Radu, R., Déqué, M., and Somot, S.: Spectral nudging in a spectral regional climate model, Tellus A, 60, 5, 898-910, 2008.

Roeckner, E., Bäuml, G., Bonaventura, L., Brokoff, R., Esch, M., Giorgetta, M., Hagemann, S., Kirchner, I., Kornblueh, L., Manzini, E., Rhodin, A., Schlese, U., Schulzweida, U., and Tompkins, A.: The atmospheric general circulation model ECHAM5. Part I: model description, Report No. 349, Max Planck Institute for Meteorology, Hamburg, Germany, 2003.

Szépszó, G. and Horányi, A.: Transient simulation of the REMO regional climate model and its evaluation over Hungary, Időjárás, $112,203-232,2008$
Uppala, S. M., Kållberg, P. W., Simmons, A. J., Andrae, U., da Costa Bechtold, V., Fiorino, M., Gibson, J. K., Haseler, J., Hernandez, A., Kelly, G. A., Li, X., Onogi, K., Saarinen, S., Sokka, N., Allan, R. P., Andersson, E., Arpe, K., Balmaseda, M. A., Beljaars, A. C. M., van de Berg, L., Bidlot, J., Bormann, N., Caires, S., Chevallier, F., Dethof, A., Dragosavac, M., Fisher, M., Fuentes, M., Hagemann, S., Hólm, E., Hoskins, B. J., Isaksen, L., Janssen, P. A. E. M., Jenne, R., McNally, A. P., Mahfouf, J.-F., Morcrette, J.-J., Rayner, N. A., Saunders, R. W., Simon, P., Sterl, A., Trenberth, K. E., Untch, A., Vasiljevic, D., Viterbo, P., and Woollen, J.: The ERA-40 re-analysis, Q. J. Roy. Meteorol. Soc., 131, 2961-3012, 2005. 